\title{
Pengaruh Lama Kerja terhadap Tingkat Organizational Citizenship Behavior (OCB) Perawat Suku Bugis di Instalasi Rawat Inap Rumah Sakit Labuang Baji
}

\section{The Effect Length of Work to the OCB Level of Bugis Tribe Nurses in the Inpatient Installation of Labuang Baji Hospital}

\author{
Andi Indahwaty Sidin*, Yahya Thamrin, Rifa'ah Mahmudah \\ Fakultas Kesehatan Masyarakat, Universitas Hasanuddin, Makassar, Indonesia \\ (*idhsidin@unhas.ac.id)
}

\begin{abstract}
ABSTRAK
Suku Bugis adalah salah satu suku yang paling banyak tersebar di Indonesia yang dikenal memiliki semangat yang tinggi, gemar berpetualang dan suka merantau.Suku Bugis memiliki nilai budaya yang tinggi yang berdampak terhadap kinerja individu dalam organisasi. Penelitian ini bertujuan untuk menganalisis pengaruh lama bekerja pada tingkat OCB perawat suku Bugis di Instalasi Rawat Inap RSUD Labuang Baji. Penelitian ini merupakan penelitian kuantitatif. Rancangan yang digunakan adalah observasional analitik dengan pendekatan cross-sectional study. Sampel sebanyak 98 orang perawat dipilih dengan teknik purposive sampling dengan kriteria suku Bugis. Data dianalisis dengan menggunakan uji regresi linear. Hasil penelitian menunjukkan bahwa seluruh perawat Suku Bugis Instalasi Rawat Inap RSUD Labuang Baji memiliki tingkat OCB yang tinggi. Hasil Uji rergesi linear antara lama kerja dan OCB menunjukkan tidak ada pengaruh antara lama bekerja dan OCB yaitu nilai $\mathrm{p}=0,203>0,005$. Sehingga disimpulkan bahwa perawat memiliki tingkat OCB yang tinggi walaupun dengan rentang lama kerja yang berbeda hal ini karena perawat suku Bugis merefleksikan nilai budaya siri' na pesse berupa matinulu (kerja keras), getteng (teguh) dan marenreng perru (setia) pada saat memberikan pelayanan di rumah sakit. Kata kunci : Lama kerja, organizational citizenship behavior, bugis
\end{abstract}

ABSTRACT

Bugis tribes is one of the most widely tribes spread in Indonesia known to have high enthusiasm, likes adventure and wandering. Their cultural value may affect to their performance in organization. This study aim was to analyze the influence length of work employment on organizational citizenship behavior of bugineese nurse in the inpatient unit at Labuang Baji Hospital. This research is a quantitative research. The design used was analytic observational with a cross-sectional study approach. A sample of 98 nurses were selected by purposive sampling technique with the Bugis tribe criteria. Data were analyzed using multiple linear regression tests. The results of the study showed that all bugineese nurses at inpatient unit at Labuang Baji Hospital had a high OCB level. The results of the linear regression test between the length of employment and OCB showed that there was no effect between length of employment and $O C B$, with value of $p=0.203>0.005$. It was concluded that nurses had a high level of $O C B$, although with different length of work, this was because the bugineese nurses had reflected the cultural value of siri "na pesse in the form of matinulu (hard work), getteng (firm) and marenreng perru (loyal) when provided services in the hospital. Keywords : Lenght of work, organizational citizenship behavior, bugis 


\section{PENDAHULUAN}

Suku Bugis adalah salah satu suku yang paling banyak tersebar di Indonesia. Mattulada menyatakan bahwa pada akhir abad ke-18 orang Bugis telah ada di berbagai tempat di luar Sulawesi Selatan. ${ }^{1}$ Menurut Forrest (Voyage from Calcutta) secara umum orang Bugis dikenal memiliki semangat yang tinggi, gemar berpetualang, suka merantau dan mampu menjalankan kegiatan paling berbahaya sekalipun. Nilai budaya Bugis dikenal dengan istilah siri' na pesse yang dijadikan sebagai pegangan hidup turun-temurun dan mempengaruhi sikap, perilaku dan tingkah laku masyarakat Bugis. ${ }^{2}$ Bagi orang Bugis siri' adalah jiwa, harga diri dan martabat, perilaku ini menuntut disiplin, kesetiaan, serta kejujuran. Berpegang pada nilai siri' maka seseorang akan sanggup rela berkorban untuk kehidupan sehari-hari dalam bekerja serta dan merupakan bentuk solidaritas sosial. Sedangkan pesse berhubungan erat dengan identitas, dan pengikat para anggota kelompok sosial atau sebuah sikap yang merujuk pada kebersamaan, dan turut merasakan kesusahan atau beban orang lain, maka dengan nilai pesse seseorang akan turut merasa bertanggung jawab untuk mengurangi beban yang ditanggung oleh keluarga dan rekan kerja. Nilai pesse dikatakan pula sebagai kekuatan pemersatu yang penting. ${ }^{1,2}$

Terdapat beberapa nilai dalam siri' na pesse yang merujuk pada peningkatan kinerja dalam organisasi misalnya matinulu (kerja keras) yaitu sebuah karakter yang akan bekerja keras untuk mencapai tujuan, getteng (teguh) yaitu karakter yang kokoh memegang pendirian serta tidak akan goyah jika diberi amanat, macca (cerdas), deceng (baik), assidengeng (kesatuan), marenreng perru (setia), sipakatau (kemanusiaan), dengan prinsip ini diharapkan individu dengan suku Bugis dapat memiliki kinerja yang mendukung dalam pemberian pelayanan berkualitas. ${ }^{3}$

Organisasi tidak dapat mengabaikan budaya atau suku/etnik kelompok dalam pengaruhinya pada kinerja individu. ${ }^{4}$ Salah satu konsep yang berhubungan erat dengan kinerja individu adalah Organizational Citizenship Behavior (OCB) yang didefinisikan oleh Organ sebagai perilaku individu yang tidak secara langsung atau eksplisit diakui oleh sistem reward tetapi secara umum mempengaruhi organisasi sehingga organisasi dapat ber- jalan secara efisien dan efektif melalui sumber perubahan, inovasi dan kemampuan adaptasi. ${ }^{5}$

OCB merupakan sebuah konsep yang terus berkembang dan menarik untuk diteliti karena dikenal sebagai alat ukur untuk perilaku organisasi yang akan berdampak kepada kinerja organisasi. ${ }^{6}$ Terdapat lima dimensi OCB yang dijelaskan secara lebih rinci sebagai berikut oleh Chahal dan Mehta: (1) Altruism, merupakan perilaku membantu orang lain atau rekan kerja tanpa diminta terlebih dahulu; (2) Sportmanship didefinisikan sebagai perilaku toleransi pada kondisi yang kurang ideal pada sebuah organisasi tanpa memperlihatkan keberatan, sehingga menciptakan iklim bekerja yang lebih baik; (3) Civic virtue, merupakan perilaku dimana karyawan aktif pada organisasinya; (4) Conscientiousness, merupakan sikap disiplin dalam bekerja, (5) Courtesy, merupakan perilaku berusaha mencegah suatu permasalahan terjadi.

Manfaat OCB menurut Podsakoff yaitu (1) Meningkatkan produktifitas dengan membantu rekan kerja baru serta membantu rekan kerja menyelesaikan tugas dengan tepat waktu; (2) Menghindari masalah antar rekan kerja (courtesy). Perilaku ini membantu manajer untuk bebas dari kegagalan krisis manajemen. Ketika pegawai dapat menghindari masalah maka manajer dapat lebih fokus pada informasi-informasi untuk pengembangan organisasi; (3) Pada seseorang yang memiliki (sportmanship) yang tinggi yang mengambil tanggung jawab baru atau belajar hal baru, Sehingga hal itu dapat menambah kemampuan organisasi untuk beradaptasi dalam perubahan lingkungan. ${ }^{8}$

Seseorang yang telah lama bekerja menurut Nwankwo memiliki kualitas dan pengalaman kerja yang menjadikannya penting bagi organisasi dan akan membentuk OCB pekerja. ${ }^{9}$ Masa kerja adalah jumlah tahun seseorang bekerja dalam sebuah organisasi yang merujuk kepada waktu mengabdi karyawan di organisasi tempatnya bekerja. ${ }^{10}$ Penelitian yang dilakukan oleh Mohammad didapatkan bahwa lama kerja berhubungan positif dengan OCB, hal ini dikarenakan bahwa seseorang yang telah lama bekerja di organisasi memiliki sikap yang positif dan perilaku yang baik terhadap organisasinya. $^{10}$

RSUD Labuang Baji Makassar merupakan 
rumah sakit kelas B milik Pemerintah Daerah Sulawesi Selatan. Rumah sakit ini sebagai salah satu rumah sakit rujukan bagi masyarakat kabupaten/ kota di provinsi Sulawesi Selatan, sehingga dituntut untuk memiliki kinerja pelayanan yang maksimal. Selain karena masyarakat Sulawesi- Selatan yang kebanyakan bersuku Bugis memiliki karakter sikap saling menghargai, saling membantu satu sama lain, sikap mempercayai yang menuntutnya untuk memberikan pelayanan yang terbaik. Pelayanan kepada pasien paling banyak diberikan oleh perawat sebagai profesi dengan sumber daya manusia terbesar di rumah sakit dan juga sebagai garis terdepan komunikasi, untuk itu baik dan tidaknya pelayanan kesehatan sangat dipengaruhi oleh perilaku dan sikap dari perawat. ${ }^{11}$ Perawat adalah karyawan rumah sakit yang merupakan "The Caring Profession" yang mempunyai kedu- dukan penting dalam menghasilkan kualitas pelayanan kesehatan di rumah sakit. ${ }^{12}$ Krause mengatakan bahwa pengalaman dan lama kerja perawat bekerja di rumah sakit sangat berkaitan erat pula dengan tingkat kualitas pelayanan kesehatan yang diberikan karena dengan intensitas yang lama bekerja perawat akan lebih baik pengetahuannya, keterampilannya serta kemampuan dalam memberikan pelayanan. ${ }^{13}$ Berdasarkan konsep yang telah dipaparkan, peneliti tertarik menganalisis pengaruh lama bekerja terhadap tingkat OCB perawat suku Bugis di instalasi rawat inap rumah sakit Labuang Baji.

\section{BAHAN DAN METODE}

Populasi penelitian ini adalah perawat Instalasi Rawat Inap RSUD Labuang Baji, pengambilan data dimulai pada Januari-Maret 2018. Sampel dipilih secara purposive sampling dengan kriteria inklusi yaitu perawat suku Bugis. Terdapat 98 perawat yang masuk pada kriteria penelitian ini. Jenis penelitian yang dilakukan adalah observasional analitik dengan pendekatan cross sectional study.

Data dikumpulkan melalui kuesioner terstruktur berisi pernyataan yang harus diisi oleh responden. Kuesioner dilakukan uji validitas dan reliabilitas, hasil uji validitas memperlihatkan seluruh rhitung $>$ rtabel dan nilai conbach alpha $>0,600$ sehingga kuesioner dinyatakan valid dan reliabel. Variabel OCB menggunakan lima indikator Organ yang dimodifikasi terdiri dari (1) altruism, sukarela dalam mengambil peran di tempat kerja dengan item pertanyaan "Ketika saya mengetahui rekan saya mengalami kesusahan dengan pekerjaanya, maka saya" (2) courtesy, menjaga hubungan baik dengan rekan kerja memiliki item pertanyaan "Ketika menghadapi permasalahan dengan rekan kerja, maka saya" (3) sportmanship, toleransi pada kondisi yang kurang ideal di tempat kerja, item pertanyaan "Saya merasa bahwa ada banyak keterbatasan kondisi kerja di organisasi ini. Apabila hal ini terjadi secara terus menerus, maka saya berencana untuk" (4) conscientiousness, disiplin saat bekerja, item pertanyaan "Hal-hal lain yang sering saya lakukan pada saat jam kerja tetapi harusnya saya lakukan pada saat jam istirahat adalah" (5) civic virtue, profesional dalam menggunakan aset dengan item pertanyaan "Jika ada pertemuan yang membahas mengenai masalah perumahsakitan khususnya yang berkaitan dengan unit tempat saya bekerja, maka". ${ }^{5}$ Terdapat 24 indikator yang dikembangkan oleh Podsakoff yang digunakan pada penelitian ini. ${ }^{14}$ Tiap pertanyaan kuesioner yang berjumlah 24 memiliki empat pilihan jawaban dengan posisi jawaban kuesioner yang diacak untuk menghindarkan responden memilih jawaban yang terbaik (terendah atau tertinggi). Skor jawaban terendah adalah satu dan skor tertinggi adalah empat.

Tabel 1. Karakteristik Responden

\begin{tabular}{lcc}
\hline \multicolumn{1}{c}{ Karakteristik } & $\mathbf{n}$ & $\mathbf{\%}$ \\
\hline Umur & & \\
$\quad$ Remaja ( $\leq 25$ tahun) & 1 & 1 \\
Dewasa (26-45 tahun) & 89 & 90,8 \\
$\quad$ Lansia (46-65 tahun) & 8 & 8,2 \\
Jenis Kelamin & & \\
$\quad$ Laki-Laki & 8 & 8,2 \\
$\quad$ Perempuan & 90 & 91,8 \\
Lama Bekerja & & \\
1 - 5 tahun & 7 & 7,1 \\
6-10 tahun & 38 & 38,8 \\
> 10 tahun & 53 & 54,1 \\
Status Kepegawaian & & \\
PNS & 67 & 68,4 \\
Kontrak & 12 & 12,2 \\
Honorer & 15 & 15,3 \\
$\quad$ Sukarela & 4 & 4,1 \\
\hline
\end{tabular}




\section{HASIL}

Tabel 1 memperlihatkan karakteristik perawat suku Bugis di Instalasi Rawat Inap RSUD Labuang Baji, sebagian besar responden berumur antara $26-46$ tahun $(90,8 \%)$ yang merupakan umur usia produktif, $91,8 \%$ responden berjenis kelamin perempuan, $54,1 \%$ responden telah bekerja lebih dari 10 tahun dan status kepegawaian responden penelitian ini 68,4 \% telah PNS. Hasil SPSS menunjukkan distribusi frekuensi OCB perawat Bugis diperoleh bahwa seluruh perawat suku Bugis (100\%) di Instalasi Rawat Inap RSUD Labuang Baji memiliki tingkat OCB yang tinggi.

Pencapaian responden pada kelima indikator OCB dapat dilihat pada Tabel 2 yaitu dengan 98\% responden memiliki altruism (kerja sama dalam tim), courtesy (menjaga citra) dan sportmanship (tidak mengeluh saat bekerja) yang tinggi, serta $96,9 \%$ responden memiliki civic virtue (profesional dalam menggunakan aset) dan conscienstousness (disiplin saat bekerja) yang tinggi pula.

Tabel 3 menunjukkan hasil crosstabulasi antara masing - masing karakteristik responden dengan tingkat OCB responden yang menunjukkan bahwa tingkat OCB perawat berdasarkan karakteristik umum responden yang seluruhnya (100\%) memiliki tingkat OCB yang tinggi, dan untuk hasil uji regresi linear antara lama bekerja dan OCB dapat dilihat pada Tabel 4 yang menunjukkan nilai p pada lama kerja terhadap OCB yaitu $0,203>0,05$. Sehingga disimpulkan bahwa lama kerja tidak mempunyai pengaruh terhadap OCB.

Tabel 2. Indikator $O C B$ Perawat Bugis

\begin{tabular}{ccc}
\hline Indikator & n & \% \\
\hline Altruism & & \\
Tinggi & 96 & 98 \\
Rendah & 2 & 2 \\
Civic Virtue & & \\
Tinggi & 95 & 96,9 \\
Rendah & 3 & 3,1 \\
Courtesy & & \\
$\quad$ Tinggi & 96 & 98 \\
Rendah & 2 & 2 \\
Conscienstousness & & \\
Tinggi & 95 & 96,9 \\
Rendah & 3 & 3,1 \\
Sportmanship & & \\
Tinggi & 96 & 98 \\
Rendah & 2 & 2 \\
\hline
\end{tabular}

\section{PEMBAHASAN}

Menganalisis pengaruh lama bekerja terhadap tingkat OCB perawat suku Bugis di instalasi rawat Inap Rumah Sakit Labuang Baji. Hasil yang ditampilkan pada karakteristik responden didapatkan bahwa seluruh responden pada kategori lama bekerja memiliki tingkat OCB yang sama tinggi sehingga tidak dapat membuktikan bahwa karyawan dengan waktu yang lebih lama bekerja memperlihatkan tingkat OCB yang lebih baik. Kemudian dilakukan uji regresi linear untuk melihat pengaruh lama bekerja terhadap tingkat OCB didapatkan bahwa tidak ada pengaruh kategori lama bekerja terhadap OCB perawat suku Bugis dengan nilai $p$ 0,203>0,05.

Tidak adanya pengaruh lama bekerja dengan OCB perawat suku Bugis diperkuat oleh beberapa penelitian terbaru menurut Huei yang mengatakan bahwa dalam lingkup budaya yang berbeda tidak ada pengaruh antara lama bekerja dengan OCB.${ }^{15}$ Selain itu, Nwankwo mengatakan bahwa perilaku OCB seseorang tidak ditentukan oleh berapa lama orang tersebut bekerja tetapi ada faktor lain seperti cultural value dan iklim organisasi. Cultural value didefinisikan oleh Hofstede sebagai sikap dan perpsepktif bersama termasuk gaya hidup, nilai-nilai dan stereotipe yang sangat mempengaruhi seseorang. ${ }^{16}$ Hasil penelitian dengan responden keseluruhan bersuku Bugis yang dikenal memiliki value semangat bekerja dan loyal sehingga lama atau tidaknya seseorang bekerja dalam organisasi tidak akan mempengaruhi kerja kerasnya dan kesetiaannya terhadap organisasi, value ini dikenal dengan istilah siri na pesse. Nilai siri' na pesse dijadikan orang bugis sebagai pegangan hidup perilaku dan tingkah laku masyarakat. Siri' yang berarti harga diri dan pesse merujuk kepada identitas diri, pengikat para anggota kelompok organisasi antara sesama orang Bugis sehingga menjadi kekuatan pemersatu yang penting. Pesse menjamin terjalinnya kohesi internal dalam suatu kelompok sosial. Salah satu ciri siri' na pesse yaitu matinulu (kerja keras). Karakter ini adalah sebuah karakter yang akan bekerja keras untuk mencapai tujuan. Selalu bekerja keras untuk mewujudkan perkataan yang telah diucapkan, karakter ini diimbangi dengan sikap rajin rẽsopa temmangingngi naletei pammase dewata (bekerja tanpa bosan 
Tabel 3. Crosstabulation Karakteristik Responden dengan Tingkat Organizational Citizenship Behavior

\begin{tabular}{|c|c|c|c|c|c|c|}
\hline \multirow{3}{*}{ Karakteristik } & \multicolumn{4}{|c|}{ Tingkat OCB } & \multirow{2}{*}{\multicolumn{2}{|c|}{ Total }} \\
\hline & \multicolumn{2}{|c|}{ Rendah } & \multicolumn{2}{|c|}{ Tinggi } & & \\
\hline & $\mathbf{n}$ & $\%$ & $\mathbf{n}$ & $\%$ & $\mathbf{n}$ & $\%$ \\
\hline \multicolumn{7}{|l|}{ Usia } \\
\hline Remaja ( $\leq 25$ tahun) & 0 & 0 & 1 & 100 & 1 & 100 \\
\hline Dewasa ( $26-45$ tahun) & 0 & 0 & 89 & 100 & 89 & 100 \\
\hline Lansia ( $46-65$ tahun) & 0 & 0 & 8 & 100 & 8 & 100 \\
\hline \multicolumn{7}{|l|}{ Jenis Kelamin } \\
\hline Laki-Laki & 0 & 0 & 8 & 100 & 8 & 100 \\
\hline Perempuan & 0 & 0 & 90 & 100 & 90 & 100 \\
\hline \multicolumn{7}{|l|}{ Lama Bekerja } \\
\hline $1-5$ tahun & 0 & 0 & 7 & 100 & 7 & 100 \\
\hline $6-10$ tahun & 0 & 0 & 38 & 100 & 38 & 100 \\
\hline$>10$ tahun & 0 & 0 & 53 & 100 & 53 & 100 \\
\hline \multicolumn{7}{|l|}{ Status Kepegawaian } \\
\hline PNS & 0 & 0 & 67 & 100 & 67 & 100 \\
\hline Kontrak & 0 & 0 & 12 & 100 & 12 & 100 \\
\hline Honorer & 0 & 0 & 15 & 100 & 15 & 100 \\
\hline Sukarela & 0 & 0 & 4 & 100 & 4 & 100 \\
\hline
\end{tabular}

Tabel 4. Hasil Uji Regresi Linear (Coefficients) Variabel Penelitian Lama Kerja pada Perawat Suku Bugis

\begin{tabular}{lccccc}
\hline \multirow{2}{*}{ Model } & \multicolumn{2}{c}{ Unstandardized Coefficients } & $\begin{array}{c}\text { Standardized } \\
\text { Coefficients }\end{array}$ & \multirow{2}{*}{ t } & Sig. \\
\cline { 2 - 4 } & $\mathbf{B}$ & Std. Error & Beta & & \\
\hline (Constan) & 76,623 & 3,128 & & 24,498 & 0,000 \\
Lama Kerja & 1,138 & 0,887 & 0,130 & 1,283 & 0,203 \\
\hline
\end{tabular}

untuk mendapat ridho Tuhan) ${ }^{3}$. Dengan idiologi ini maka perawat suku Bugis Makassar dapat menimbulkan OCB yang tinggi tidak terpengaruh dari selama apa perawat tersebut bekerja dalam organisasi.

Aman dan Tang mengatakan terdapat beberapa ciri siri na pesse yang diwariskan secara turun temurun yaitu lempuk/jujur ; matinulu/kerja keras; deceng/ baik; marenreng perru/setia; asseddingeng/kesatuan; macca/cerdas. Hal ini sesuai dengan definisi dari organizational citizenship behavior yaitu perilaku sukarela untuk meningkatkan efektifitas organisasi dengan lima variabel organizatinal citizenship behavior yaitu altruism yang merujuk pada perilaku membantu rekan kerja tanpa diminta terlebih dahulu; courtesy yaitu perilaku yang berusaha mencegah suatu permasalahan terjadi. Variabel altruism dan courtesy sesuai dengan value deceng yang diartikan sebagai perilaku baik, yang senang membantu orang lain, suka berinteraksi serta melakukan sesuatu sesuai dengan etika dan norma sehingga selalu berusaha agar tidak terjadi masalah dan value asseddingeng yang diartikan sebagai perilaku saling membantu dan saling memberi perhatian. Civic virtue yaitu perilaku turut berpartisipasi dan bertanggung jawab dalam organisasi sesuai dengan value matinulu yaitu karakter yang akan bekerja keras untuk mencapai tujuan; sportmanship yaitu perilaku toleran yang berusaha memahami halhal yang mengganggu tanpa mengeluh dengan melihat segala sesuatu lebih komprehensif dan tidak fokus terhadap kesalahan hal ini sesuai dengan value matinulu yang berarti kerja keras dan value macca yaitu karakter dengan kemampuan berpikir keras dan cepat dalam memahami sesuatu dan mampu menemukan jalan keluar. 
Consciountousness perilaku berhati-hati, jujur dan disiplin waktu yang sesuai dengan value lempuk yaitu perilaku jujur.

Distribusi frekuensi indikator pada hasil penelitian ini terlihat bahwa $98 \%$ responden memiliki tingkat altruism yang tinggi, altruism menurut Chahal dan Mehta adalah perilaku membantu rekan kerja yang kelebihan kerja dan mencari permasalahan yang dihadapi ${ }^{7}$ atau secara sederhana altruism menurut Organ didefinisikan sebagai kerja sama dalam tim. ${ }^{5}$ Poin kuesioner dalam penelitian ini yang menanyakan kepada responden tentang kesiapannya memberikan bantuan kepada rekan kerjanya yang tidak hadir sekitar $78,6 \%$ responden menjawab siap mengambil alih pekerjaan pada saat rekan kerjanya berhalangan hadir.

Hasil penelitian juga memperlihatkan responden memiliki tingkat civic virtue yang tinggi. Civic virtue yang menurut Chahal dan Mehta sebagai perilaku yang turut berpartisipasi, bertanggung jawab dan penuh kesadaran menunjukkan perhatian demi kelangsungan hidup organisasi, ${ }^{7}$ atau menurut Organ civic virtue didefinisikan sebagai perilaku yang memberikan dukungan kepada fungsi administrasi dan organisasi. ${ }^{5}$ Pada poin kuesioner yang menanyakan "jika terjadi perubahan pimpinan dalam organisasi maka hal yang dilakukan adalah" sebanyak $77,6 \%$ responden mampu menyesuaikan diri dengan kebijakan pimpinan baru. Selain itu ketika ditanyakan mengenai kesediaan mengikuti pertemuan-pertemuan debat kebijakan yang tidak dimandatkan kepadanya tetapi penting bagi organisasi $78,6 \%$ responden menjawab bersedia mengikuti sosialisasi untuk meng update pengetahuannya.

Indikator courtesy menunjukkan $98 \%$ responden memiliki tingkat courtesy yang tinggi. Courtesy menurut Chahal dan Mehta sebagai perilaku yang berusaha mencegah suatu permasalahan yang terjadi, ${ }^{7}$ menurut Organ courtesy didefinisikan sebagai perilaku menjaga hubungan baik dengan rekan kerja sehingga terhindar dari masalah yang mungkin terjadi antar rekan kerja. ${ }^{5}$ Pada poin kuesioner yang menanyakan "jika berbeda pendapat dengan rekan kerjanya maka hal yang dilakukan adalah " $73,5 \%$ responden menjawab akan mencari jalan tengah yang hasilnya baik untuk rekan kerja dengan tetap mempertimbangkan pendapatnya.

Responden dari hasil penelitian memperlihatkan juga memiliki tingkat consciountesness yang tinggi. Consciountesness menurut Organ berarti disiplin saat bekerja atau perilaku yang mengindikasikan karyawan untuk menerima aturan, regulasi dan prosedur yang ada dalam organisasi. ${ }^{5}$ Pada poin kuesioner yang menanyakan "jika jam kerja di rumah sakit dimulai jam 8 maka yang dilakukan adalah " $88 \%$ responden menjawab akan datang sebelum jam kerja dimulai.

Tingkat sportmanship responden berada pada kategori yang tinggi yaitu sekitar 98\% responden memiliki tingkat sportmanship yang tinggi. Chahal dan Mehta mendefinisikan sportmanship sebagai perilaku toleran dan berusaha memahami hal-hal yang sifatnya menganggu, ${ }^{7}$ menurut Organ sportmanship berarti tidak mengeluh saat bekerja atau sebuah perilaku yang didefinisikan sebagai perilaku tolerensi pada kondisi yang kurang ideal pada sebuah organisasi tanpa memperlihatkan keberatan, sehingga menciptakan iklim bekerja yang lebih baik. ${ }^{5}$ Pada poin kuesioner yang menanyakan "jika merasa kekurangan alat pendukung di tempat kerja maka yang dilakukan adalah " $74,5 \%$ responden menjawab berusaha untuk tetap bekerja dan bertahan dan melihat situasi. Serta pada poin kuesioner yang menanyakan sikap responden ketika menemukan banyak kesalahan yang berulang-ulang yang terjadi dalam organisasi maka $64,5 \%$ responden menjawab akan membagi tugas secara adil dan memotivasi rekan kerja untuk menyelesaikan pekerjaannya.

Namun, hal ini berbeda dengan hasil penelitian yang mengatakan bahwa terdapat hubungan yang positif antara lama kerja dan OCB, karyawan yang lebih lama bekerja cenderung lebih memahami organisasi sehingga meningkatkan kinerja mereka karena adanya motivasi kerja yang lebih tinggi dibandingkan dengan karyawan yang baru bekerja. ${ }^{17,18,19,20,21}$ Begitu pula hasil penelitian yang dilakukan oleh Ramadhani yang mengemukakan bahwa lama bekerja karyawan berkolerasi dengan tingkat OCB karyawan, menurut Ramadhani semakin lama bekerja maka semakin tinggi tingkat OCB karyawan, karyawan akan merasa hidupnya lebih bermakna karena ke- 
setiaan karyawan terhadap organisasi yang lebih tinggi dan mereka berasumsi bahwa organisasi mendukung mereka dan dapat mengarah pada ikatan yang kuat pada organisasi. ${ }^{22}$ Adanya korelasi lama kerja dan OCB juga dikatakan oleh Mohammad dalam penelitiannya yang memperlihatkan hubungan positif antara lama bekerja dan OCB, menurut Muhammad semakin lama bekerja maka keterikatan, rasa memiliki, tanggung jawab terhadap organisasi akan meningkat sehingga inilah yang menjadikan organisasi dapat bertahan, Mohammad juga mengatakan bahwa semakin lama bekerja karyawan maka semakin banyak waktu yang dihabiskan pekerja dalam organiasi maka akan menjadikan karyawan akan semakin beradaptasi dengan aturan, prosedur, kebijakan struktur serta budaya dalam organisasi sehingga mereka menjadi sadar akan tujuan dari organisasi tersebut dan berupaya untuk mencapai tujuan organisasi. ${ }^{10}$

Hubungan lama kerja dan OCB tampaknya terlihat dari dua asumsi yang meluas yaitu, pertama karyawan dengan masa kerja yang lebih lama harus lebih kompeten dan tampil lebih prima dari pada rekan mereka yang memiliki masa kerja yang lebih pendek. Kedua, organisasi setidaknya secara implisit mengharapkan karyawan yang lebih lama bekerja lebih banyak pengalaman untuk bersosialisasi, membantu dan membimbing karyawan junior dan ini cenderung pada perilaku tanggung jawab yang berorientasi pada emosional dan psikologis.

\section{KESIMPULAN DAN SARAN}

Hasil penelitian menunjukkan tidak ada pengaruh lama kerja terhadap OCB perawat suku Bugis. Perawat suku Bugis merefleksikan nilai budaya siri' na pesse berupa matinulu (kerja keras), getteng (teguh) dan marenreng perru (setia) pada saat memberikan pelayanan di rumah sakit sehingga lama tidaknya rentang waktu perawat bekerja di rumah sakit tetap memperlihatkan OCB yang merupakan perilaku extra role yang tinggi. Dari hasil penelitian yang dilakukan saran yang diberikan adalah penelitian ini dapat digunakan oleh manajemen rumah sakit sebagai sumber informasi dan laporan analisis untuk dimanfaatkan dalam peningkatan kinerja extra-role perawat yang bekerja di rumah sakit. Selain itu pimpinan rumah sakit dapat memperhatikan pengaruh nilai budaya yang mendukung performa perawat sehingga kinerja dapat dipertahankan, selain itu disarankan agar peneliti selanjutnya melakukan penelitian dengan karakteristik suku yang berbeda sehingga hasil penelitian selanjutnya dapat dibandingkan dengan hasil penelitian saat ini ini.

\section{DAFTAR PUSTAKA}

1. Mattulada, M.T. Latoa: Antropologi Politik Orang Bugis. Jogjakarta: Penerbit Ombak.

2. Omar, A. T.,Amat, A. Etika Kerja Etnik Bugis di Sabah: Satu Kajian di Organisasi Awam'. MANU Bil. 2017; (25):75-86.

3. Amin, K. F.., Tang, M. R. The Ideology of Buginese in Indonesia (Study of Culture and Local Wisdom. Journal of Language Teaching and Research. 2015; 6(4):758-765.

4. Cohen, A. The Relationship Between Multiple Commitments and Organizational Citizenship Behavior in Arab and Jewish Culture. Journal of Vocational Behavior [Online Journal]. 2006;69(1):105-118. [Diakses 24 Februari 2019]. Available at: https://www. sciencedirect.com/science/article/abs/pii/ S0001879105001387

5. Organ, D. W. Organizational Citizenship Behavior. Elsevier; 2015.

6. Podsakoff, N. P., Podsakoff, P. M., Mackenzie, S. B., Maynes, T. D., Spoelma, T. M. Consequences of Unit-Level Organizational Citizenship Behaviors : A Review and Recommendations for Future Research. Journal of Organizational Behavior [Online Jurnal]. 2014;35(S1):87-119. [Diakses 24 Februari 2019]. Available at: https://onlinelibrary.wiley.com/doi/abs/10.1002/job.1911.

7. Chahal, H., Mehta, S. Antecedents and Consequences of Organizational Citizenship Behaviour (OCB): A Conceptual; Framework in Reference to Health Care Sector. Journal of Services Researchn[Online Jurnal], 2010;10(2):25-44. [Diakses 24 Februari 2019]. Available at: https://www.researchgate.net/publication/310795722.

8. Podsakoff, N. P., Whiting, S. W., Podsakoff, P. M., Blume, B. D. Individual- and Organizational-Level Consequences of Organizational Citizenship Behaviors: A Me- 
ta-Analysis. Journal of Applied Psychology. 2009;94(1): 122-141.

9. Nwankwo, B. E., Obi, T. C., Agu, S. A., Aboh, J. U. Influence of Pay Satisfaction and Length of Service on Organization Citizenship Behaviour of Bankers. International Journal of Academic Research in Business and Social Sciences. 2013;3(9):238-244.

10. Mohammad, J., Quoquab, F., Zakaria, S. Organizational Citizenship Behavior and Commitment: Do Age and Tenure Make Any Difference?. BMQR. 2010:1(3);28-49.

11. Taghinezhad, F., Safavi, M., Raiesifar, A. and Yahyavi, S. H. (2015). Antecedents of Organizational Citizenship Behavior among Iranian nurses: A Multicenter study. BMC Research Notes. 2015:8(547):1-8.

12. Depkes RI. Direktorat Bina Pelayanan Keperawatan dan Pelayanan Medik Kementrian Kesehatan RI. Jakarta: Departemen Keseha$\tan ; 2001$.

13. Krause, M. R. Director of Nursing Current Job Tenure and Past Experience and Quality of Care in Nursing Homes. Health Care Management Review [Online Journal]. 2013; 37(1):98-108. [Diakses 24 Februari 2019]. Available at: https://www.ncbi.nlm.nih.gov/ pubmed/21712721.

14. Podsakoff, M., Mackenzie, S. B.. Consequences of Unit Level Organizational Citizenship Behavior : A Review and Recommendations for Future Research. Journal of Organizational Behavior. 2014:35(S1):87119.

15. Huei, T.Y., Mansor, N.N.A., Tat, H.H. Role of OCB and Demographic Factors in the Relationship of Motivation and Employee Performance. Omnia Science [Online Journal]. 2014;10(3):425-447.[Diakses 24 Februari 2019]. Available at: http://www.intangiblecapital.org/index.php/ic/article/view/435.

16. Hofstede, G, Dimensionalizing Cultures: The Hofstede Model in Context. Psychology and Culture. 2011;2(1):1-26.

17. Chou, S.Y.,Pearson, J. A Demographic Study of Information Technology Professionals Organizational Citizenship Behaviour. Journal of Management Research [Online Journal]. 2011; 3(2):1-15.[Diakses 24 Februari 2019]. Available at : https://www.researchgate.net/ publication/277771841 .

18. Gyekye, S.A., Haybatollahi, M., Stokes, P., Stokes, P. Organizational Citizenship Behaviour: An Empirical Investigation of the Impact of Age and Job Satisfaction on Ghanaian Industrial Workers. International Journal of Organizational Analysis [Online Journal]. 2015;23(2):285-301. [Diakses 24 Februari 2019]. Available at: https://psycnet.apa.org/ record/2015-21183-007.

19. Pavalache-Ilie, M. Organizational Citizenship Behaviour, Work Satisfaction and Employees' Personality. Social and Behavioral Sciences. [Online Journal]. 2014;127:489493. [Diakses 24 Februari 2019]. Available at: https://www.sciencedirect.com/science/ article/pii/S1877042814023878.

20. Singh, A.K., Singh, A. Role of Stress and Organizational Support in Predicting Organizational Citizenship Behavior. The IUP Journal of Organizational Behavior [Online Journal]. 2010;9(4):7-25.

21. Monga, J. M., Flotman, A., Cilliers, F. V. Organisational Citizenship Behaviour among Railway Employees in a Developing Country : Effects of Age, Education and Tenure. Southern African Business Review [Online Journal]. 2017:21;385-406. [Diakses 24 Februari 2019]. Available at: https://core. ac.uk/download/pdf/151156255.pdf.

22. Ramdhani, N., Ancok, D., Adrianson, L., Psychology, F.,Mada, U. G. The Importance of Positive Affect: The Role of Affective Personality in Predicting Organizational Citizenship Behavior. Makara Hubs-Asia [Online Journal]. 2017:21(2);62-69. [Diakses 24 Februari 2019]. Available at: http://hubsasia.ui.ac.id/old/index.php/hubsasia/article/ view/3501. 